\title{
Sustainable implementation of innovative technologies for water purification
}

\section{Bart Van der Bruggen $\mathbb{D}^{1,2}$}

One of the sustainable development goals set by the United Nations General Assembly is to ensure the availability and sustainable management of water and sanitation for all. This requires investment in water purification technologies. World Water Day offers an opportunity to discuss whether such investment will help achieve this laudable goal.

Wastewater and seawater have long been considered as potential sources from which to produce freshwater. Several technologies have been developed over the past few decades aimed at their reuse and recycle, but unfortunately the treatment of both sources may have perfidious effects.

Of the approaches presently available, desalination seems to have the greatest potential, given that seawater is a nearly unlimited resource. However, desalination is an energy-intensive process. The state-of-the-art technology, seawater reverse osmosis (SWRO), has undergone huge improvements over the past five decades: the specific energy consumption of SWRO was reduced from $20 \mathrm{kWh} \mathrm{m}^{-3}$ in 1970 to only $2.5 \mathrm{kWh} \mathrm{m}^{-3}$ in 2010 . It has been estimated that a further $0.69-0.79 \mathrm{kWh} \mathrm{m}^{-3}$ might be saved by a smart process integration with intrinsic heat recovery ${ }^{1}$, but desalination of typical seawater (with an average salt concentration of $35 \mathrm{gl}^{-1}$ ) requires a minimum of $1.07 \mathrm{kWh} \mathrm{m}^{-3}$, offering only a little room for improvement. This limit is the foundation of the waterenergy nexus and prompts further research on renewable energy sources for desalination, which remain scarce. In a case study, Delgado-Torres and co-workers ${ }^{2}$ used tidal and solar energy for desalination at a semi-arid location in Broome, Australia. Similar studies focus on desalination driven by wind energy, photovoltaics or solar thermal energy. Although such approaches to water desalination may be viable to supply clean water in small or spatially confined communities - as was demonstrated in the island of $\mathrm{Aruba}^{3}$ - they offer very little for the water challenges of large cities such as Beijing, Cairo or Cape Town.

In a cost-benefit analysis, wastewater recycling is more favourable than seawater desalination, because the former does not require the expensive separation of salts from water. This may seem surprising given that reverse osmosis is the key technology in both cases. The difference is that wastewater recycling would operate at much lower pressure. Such recycling has been practised for more than half a century in Windhoek, Namibia, and is accepted practice in water-scarce places such as Singapore ${ }^{4}$. Southern California is presently implementing a large-scale scheme to use recycled water as a potable source ${ }^{5}$ and other countries and locations will surely follow. This trend pushes researchers to develop fouling-resistant, high-flux membranes for reverse osmosis and related membrane processes such as nano- or ultrafiltration. However, new challenges also arise. The production of (polymer) membranes for purification typically requires the use of polar aprotic solvents such as $\mathrm{N}, \mathrm{N}$-dimethylformamide (DMF), $N, N$-dimethylacetamide (DMA), 1,4-dioxane and

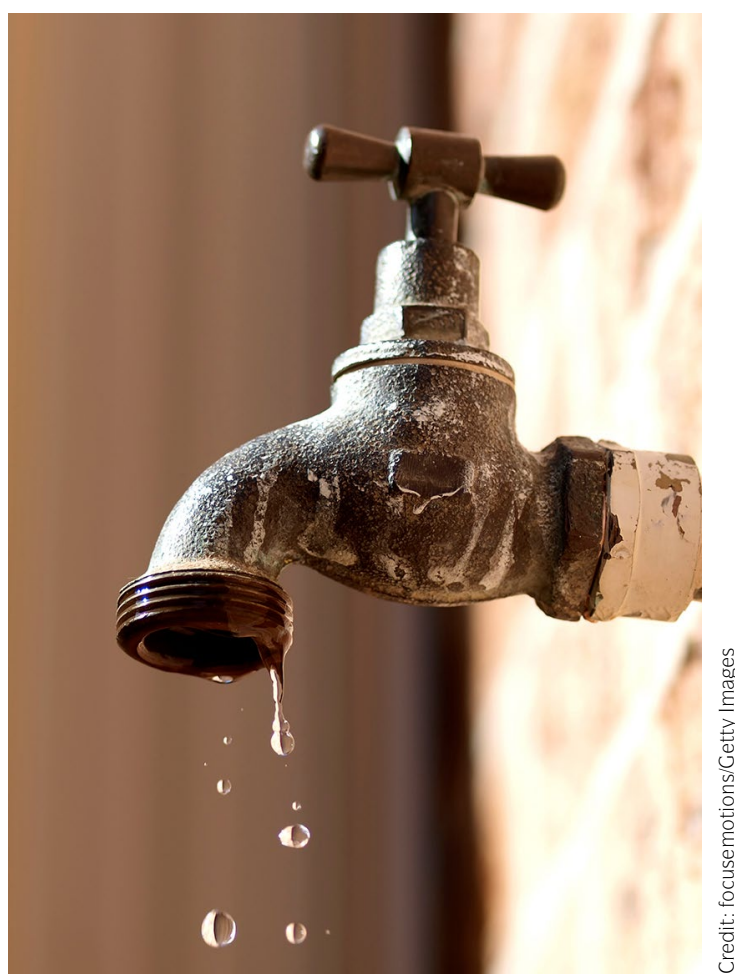


tetrahydrofuran (THF). These solvents have a considerable environmental impact and significant effort is invested in their replacement with 'greener' solvents such as organic carbonates ${ }^{6}$ or dimethyl sulfoxide (DMSO) ${ }^{7}$. Another limitation for present membrane technologies lies in the availability, processing and scale-up of materials for their manufacture. For example, two 2006 reports describe how incorporating carbon nanotubes into membranes affords permeabilities one to two orders of magnitude larger than those of conventional membranes. However, scaling up the synthesis of such membranes was not expected to be easy ${ }^{8}$ - and, indeed, it has, so far, not happened. Since these reports emerged, there have been numerous studies on mixedmatrix membranes combining other nanostructures with polymeric matrices but, thus far, none has yet been applied on a large scale. Typically, good results are obtained in the laboratory, but the cost of producing the required nanostructures or issues associated with toxicity or leaching of nanoparticles from membranes have proven prohibitive for industrial use. Researchers need to place greater focus on the development of realistic membranes rather than just better membranes.

Closing the water cycle by either desalination or wastewater purification promises to provide virtually unlimited volumes of freshwater: in principle, it would enable an increase in water consumption by a factor equal to the inverse of the recycled fraction. However, we must be cognizant of unintended consequences. Water availability is one of the limiting factors for population growth and greater availability would certainly stimulate population growth. History has shown that humankind naturally makes use of available resources, sometimes with dramatic consequences, as exemplified by the agricultural and industrial revolutions ${ }^{9}$. A historical, sociological and demographic analysis by Harari shows that if water recycling is practised on a large scale, water consumption per capita may remain the same but our population will grow by the inverse of the recycled fraction? This would then automatically lead to new challenges. A disenchanting example is the present SARS-CoV-2 virus: the scale of the outbreak would have been much more contained in a modest, local society without overpopulation. Water technologies may catalyse global growth more than any other technology because water is one of very few commodities that humankind cannot do without. This is of course not the case for industrialized countries, where water is not a limiting factor, but in most parts of the world it is. Harari was criticized for being unfamiliar with technologies, and, while this may be a fair criticism, warnings from other disciplines should not be summarily dismissed by technology developers.

In conclusion, the scope of water technologies may need to be reconsidered. There is no need for a major technological breakthrough in water recycling or desalination. What is really needed is for present technologies to be available to children growing up without access to clean water sources, as stated in the United Nations sustainable development goals. This will require dedicated, embedded actions towards maintaining the demographic status quo while respecting the basic human rights of all. The goals then are a useful tool to monitor progress but must be considered in context because the indicators that are used can result in tunnel vision ${ }^{10}$. Furthermore, lifestyle choices in terms of water - reduce, reuse and recycle - need to be thoroughly considered and be more than just a hollow slogan.

1. Park, K., Kim, J. B., Yang, D. R. \& Hong, S. K. Towards a low-energy seawater reverse osmosis desalination plant: a review and theoretical analysis for future directions. J. Membr. Sci. 595, 117607 (2020).

2. Delgado-Torres, A. M., García-Rodrīguez, L. \& Jiménez del Moral, M. Preliminary assessment of innovative seawater reverse osmosis (SWRO) desalination powered by a hybrid solar photovoltaic (PV) - tidal range energy system. Desalination 477, 114247 (2020).

3. Brendel, L. P. M., Shah, V. M., Groll, E. A. \& Braun, J. E. A methodology for analyzing renewable energy opportunities for desalination and its application to Aruba. Desalination 493 114613 (2020).

4. Lafforgue, M. \& Lenouvel, V. Closing the urban water loop: lessons from Singapore and Windhoek. Environ. Sci. Water Res. Technol. 1 622-631 (2015).

5. Chalmers, R. B., Tremblay, M. \& Soni, R. A new water source for Southern California: the regional recycled water program. J. AWWA 112, 6-19 (2020).

6. Rasool, M. A., Pescarmona, P. P. \& Vankelecom, I. F. J. Applicability of organic carbonates as green solvents for membrane preparation ACS Sustain. Chem. Eng. 7, 13774-13785 (2019).

7. Evenepoel, N., Wen, S., Tsehaye, M. T. \& Van der Bruggen, B. Potential of DMSO as greener solvent for PES ultra- and nanofiltration membrane preparation. J. Appl. Polym. Sci. 135 46494 (2018).

8. Sholl, D. S. \& Johnson, J. K. Making high-flux membranes with carbon nanotubes. Science 312, 1003-1004 (2006)

9. Harari, Y. N. Sapiens: A Brief History of Humankind (Harper Collins, 2015).

10. Weststrate, J., Dijkstra, G., Eshuis, J., Gianoli, A. \& Rusca, M. The sustainable development goal on water and sanitation learning from the millennium development goals. Soc. Indic. Res. 143, 795-810 (2019).

\section{Competing interests}

The author declares no competing interests.

RELATED LINKS

United Nations sustainable development goals: https://sdgs.un.org/goals 